Currículo sem Fronteiras, v. 19, n. 3, p. 868-892, set./dez. 2019

\title{
CONSERVADORISMO E SEUS IMPACTOS NO CURRÍCULO ESCOLAR
}

\author{
José Antonio Sepulveda \\ Universidade Federal Fluminense - UFF \\ Denize Sepulveda
}

Universidade do Estado do Rio de Janeiro - UERJ

\begin{abstract}
Resumo
O intuito deste artigo é avaliar os impactos do conservadorismo na educação escolar, em especial no debate curricular. Tal debate foi marcado pela presença de movimentos conservadores organizados que, entre outras coisas, pautaram a defesa de um novo status para a disciplina escolar Ensino Religioso e agiram de forma articulada para enfrentarem o que eles chamaram de "ideologia de gênero". Para isso, fizemos uma ampla discussão sobre o conceito de conservadorismo e demonstramos, por meio de pesquisa, sua presença em uma escola pública do estado do Rio de Janeiro. Concluímos que vivemos um ataque conservador às instituições educacionais e que a luta pela laicidade na educação é um instrumento fundamental para se garantir uma sociedade democrática e soberana.
\end{abstract}

Palavras-chave: educação, laicidade, conservadorismo e “ideologia de gênero”.

\begin{abstract}
The purpose of this article is to evaluate the impacts of conservatism on school education, especially in the curricular debate. This debate was marked by the presence of organized conservative movements that, among other things, guided the defense of a new status for the Religious Education school discipline, and acted in an articulate manner to confront what they called "gender ideology". For this, we made a broad discussion about the concept of conservatism and demonstrated through research its presence in a public school in the state of Rio de Janeiro. We conclude that we are living a conservative attack on educational institutions and that the struggle for secularism in education is a fundamental instrument to guarantee a democratic and sovereign society.
\end{abstract}

Keywords: education, secularism, conservatism and "gender ideology”.

ISSN 1645-1384 (online) www.curriculosemfronteiras.org

http://dx.doi.org/10.35786/1645-1384.v19.n3.04 


\section{Introdução}

Este artigo pretende contribuir para a compreensão dos impactos do conservadorismo na educação brasileira, em especial na educação escolar. O texto está dividido em três partes. A primeira discute o conceito de conservadorismo. A segunda aponta duas características desse conservadorismo na educação brasileira: a presença e a importância relegada ao Ensino Religioso na Base Nacional Comum Curricular (BNCC) e a perseguição à chamada "ideologia de gênero". A terceira parte deste artigo trata dos impactos dessas duas propostas na educação escolar brasileira.

O referencial metodológico usado foi o paradigma indiciário de Carlo Ginzburg (1989), a fim de encontrarmos pistas, indícios e sinais de práticas conservadoras tecidas em uma escola pública no município de São Gonçalo no Estado do Rio de Janeiro. Segundo Ginzburg (1989), o paradigma indiciário nos possibilita entender alguns significados daquilo que não temos capacidade de compreender de outro modo, captar neles informações do real não acessíveis pelos meios tradicionais de pesquisa; é esse o fundamento do paradigma indiciário.

Esta metodologia se converte num instrumento para ajudar a pesquisadora e o pesquisador a ver através das névoas que obscurecem as relações sociais. "Se a realidade é opaca, existem zonas privilegiadas - sinais, indícios - que permitem decifrá-la" (GINZBURG, 1989, p. 17). Assim, o paradigma indiciário é um referencial teóricometodológico que viabiliza interpretações diferentes da realidade, já que não se utiliza de evidências que, muitas vezes, podem dificultar a construção de formas diferentes de leitura do problema observado.

Ginzburg (1989, p. 151) defende que durante anos o homem foi caçador e que "aprendeu a reconstituir as formas e movimentos das presas invisíveis pelas pegadas na lama, ramos quebrados, bolotas de esterco, tufos de pelos, plumas emaranhadas, odores estagnados”. Para o autor, para além de uma documentação verbal e escrita, o homem desenvolveu outras formas de conhecer. Segundo ele, o pesquisador deve ir à procura de pistas, indícios e sinais, mobilizando todos os seus sentidos. Empregando o paradigma indiciário apresentado por Ginzburg, também procuramos captar os pormenores negligenciáveis, seguimos pistas e recolhemos indícios sobre algumas práticas conservadoras que ocorrem em uma escola.

Os principais autores usados como referencias teóricas para compreender como se processa o desenvolvimento histórico do conservadorismo foram: Thompson (1981, 2012), Bonazzi (2000), Hirschman (1992), Mannheim (1959, 1972) e Löwy (1991). Para dialogar com o conceito de cultura empregamos Raymond Williams (2011), pois este autor nos ajudou a compreender que a reação conservadora de certas pessoas diante de uma nova proposta de sociedade é uma forma de defesa da tradição de seus costumes e de suas posições políticas. Sobre a defesa da laicidade do estado como elemento primordial para a manutenção da democracia, contra as propostas fundamentalistas religiosas, utilizamos Cunha $(2016,2018)$. O pensamento de Penna (2017) foi aplicado sobre as considerações em relação ao movimento Escola Sem Partido, pois este é um movimento conservador que vem afetando as legislações educacionais, os currículos escolares e as práticas tecidas em muitas escolas. 
Nas considerações finais, sinalizamos que o conservadorismo é uma narrativa que naturaliza e defende a desigualdade social e vem se intensificando no campo educacional a partir da ação de bancadas religiosas no universo legislativo brasileiro.

\section{O conservadorismo}

O termo conservadorismo carrega consigo um problema muito específico, uma vez que ele se relaciona de alguma forma com o comportamento humano. Tal característica prejudica muito a compreensão do termo, pois o deixa impregnado de uma carga emocional que só atrapalha a construção de uma concepção mais científica de conservadorismo.

A existência de uma carga emotiva no uso desse conceito nos ajuda a entender um dos principais problemas da sociedade contemporânea: a polaridade de argumentos, que coloca os termos dos debates públicos em constante tensão, reforçando uma visão binária de mundo. Essa análise reduz as possibilidades de múltiplas interpretações para a realidade social, as submetendo a uma mesma tipologia, no caso, à oposição entre conservadorxs ${ }^{1}$ e progressistas.

Xs progressistas seriam aqueles que possuem uma atitude otimista quanto às possibilidades de desenvolvimento dos direitos humanos. E os conservadores se apresentam como aqueles que negam tais possibilidades. Essa forma de compreensão reduz as práticas conservadoras à existência de práticas progressistas. Ou seja, só seria possível entender o conservadorismo com base em práticas opostas.

Por considerarmos essa concepção muito superficial e limitada, pretendemos fugir da busca de um conceito definitivo e analisar o conservadorismo como um processo; portanto, a partir de uma perspectiva histórica. Por causa disso, não podemos examinar a sociedade nem de forma binária e nem de forma reducionista, pois assim suprimimos a construção processual dos conceitos. Ou seja, não é possível se congelar a história em estruturas rígidas de análise, pois o processo histórico é sempre desigual e contraditório, como bem define Thompson (1981, p. 105):

Mas em qualquer conjuntura particular, quando poderíamos escolher deter a história ou tomar dela uma "seção", a "última instância" (que lembramos, não chega nunca) provavelmente não estará por perto. Esse tipo de sincronia, que procura um instante simultâneo da "totalidade", interpretará inadequadamente as evidências. Além do mais, a maioria das outras "instâncias” ou "níveis" da estrutura se apresentará de maneira imprópria, já que todos estão se movendo em planos diferentes.

Sendo assim, a partir dessa perspectiva histórica processual, o conservadorismo não pode ser somente uma tese reativa, como nos faz entender Bonazzi (2000). Discordamos também da tese de que o conservadorismo não produza conhecimento e nem agentes políticos. Há séculos existem partidos políticos conservadores proativos, principalmente no que tange ao 
desenvolvimento econômico e tecnológico. Muitos autores, como Hirschman (1992), não acreditam que a simples proposta de transformação social seja sempre progressista. O fato de existirem mudanças sociais com argumentos transformadores não necessariamente gera benefícios para a humanidade. Exemplo disso são as propostas de reformas neoliberais que atacam diretamente direitos trabalhistas e previdenciários com o discurso de modernizar os sistemas financeiros, adequando-os às necessidades do mundo contemporâneo, o que alguns autores, como Barrington Moore Jr. (1975), chamam de modernização conservadora. Na prática, essas propostas significam perdas para xs trabalhadorxs. Sendo assim, reagir a isso é uma atitude digna da classe trabalhadora; ou seja, o dito progresso nem sempre é positivo.

Com efeito, podemos entender que a compreensão do conservadorismo passa necessariamente por entendê-lo no âmbito do campo ${ }^{2}$ de debate da política. E que não nos interessa a questão da moral e do comportamento humano e sim o debate coletivo e político do termo. Baseando-nos em Hirschman (1992), que construiu uma obra sobre o conservadorismo na qual analisou 200 anos de sua retórica, concluímos que tal oratória se apresenta como enfrentamento de qualquer mudança de ordem política que se proponha, de alguma forma, a modificar as relações de poder estabelecidas em uma sociedade. Hirschmam (1992), Bonazzi (2000) e outrxs autorxs identificam que a inauguração do conservadorismo político se dá na obra de Edmund Burke (2012) e sua crítica à Revolução Francesa.

O conservadorismo surge como resposta necessária às teorias que, a partir do século XVIII, se distanciaram da visão antropológica tradicional, para reivindicar para o homem a possibilidade, não só de melhorar o próprio conhecimento e seu domínio sobre a natureza, como também de alcançar, por meio de ambos, uma autocompreensão cada vez maior e, consequentemente, a felicidade. O resultado a que tendiam estas teorias era o de fazer da história humana um processo aberto e ascendente, baseado numa antropologia revolucionária, onde o indivíduo fosse núcleo ativo, capaz de se tornar melhor tornando-se cada vez mais racional. (BONAZZI, 2000, p. 243).

Com efeito, para xs conservadorxs, qualquer possibilidade de mudança produzia um abalo na tradicional e estática concepção de mundo herdada da Idade Média. A perspectiva cristã, oficial no mundo ocidental, relacionava diretamente as atitudes humanas e, consequentemente, a atitude política a uma espécie de providência divina. Muitxs autorxs, como De Maistre (1821) e De Bonaldi (1802), defendiam que qualquer tentativa de mudança social e política seria inútil e que acarretaria uma espécie de vingança divina, que levaria todas as mudanças a retornarem a um ordenamento religioso (HIRSCHMAN, 1992).

Com base na constatação anterior, Hirschmam (1992, p. 15) passa a identificar três teses recorrentes da retórica conservadora: tese da perversidade, tese da futilidade e tese da ameaça.

De acordo com a tese da perversidade, qualquer ação proposital para melhorar um aspecto da ordem econômica, social ou política só serve para exacerbar a situação que se deseja remediar. A tese da futilidade sustenta que as tentativas de 
transformação social serão infrutíferas, que simplesmente não conseguirão 'deixar uma marca'. Finalmente, a tese da ameaça argumenta que o custo da reforma ou mudança proposta é alto demais, pois coloca em perigo outra preciosa realização anterior.

A tentativa de Hirschman (1992) de construir um conjunto de teses que determinem uma retórica conservadora acaba reduzindo as possibilidades de interpretação de sua dinâmica. As próprias mudanças sociais, inclusive as utilizadas por Hirschman (1992), demonstram haver um processo de adequação do discurso, fruto de disputas internas inerentes ao próprio campo conservador, o que não é devidamente trabalhado pelo autor. Tal limitação, em seu trabalho, se origina de uma opção teórico-metodológica que não leva em conta a diversidade e a complexidade das relações humanas, principalmente por não visibilizar a dinâmica das relações de classe social.

Divergimos, apesar da boa análise do autor, de sua tipologia. Todavia, o cenário de análise do Hirschman (1992) nos parece correto. Ou seja, quando os argumentos são empregados para evitar qualquer transformação na ordem social ou melhorias reais para as classes trabalhadoras ou para qualquer grupo minoritário, temos uma retórica conservadora.

Na forma como o entendemos, o conservadorismo é uma categoria histórica, ou seja, que deriva de processos cujos resultados são diferenciados, ao longo do tempo. Entendemos o conservadorismo como algo estabelecido a partir de uma cultura conservadora, resultado da regularidade de argumentos empregados em situações análogas entre si por diversos agentes históricos. Dessa forma, não é possível se pensar em conservadorismo como uma categoria estática, tanto sociológica quanto antropologicamente. Ou seja, a história é marcada por disputas, em especial por aquilo que se vinculou chamar de luta de classes. Na disputa por poder que ocorre no campo da cultura, o conservadorismo é um importante elemento na construção dos interesses de classe e da própria consciência de classe. Em tal processo, não estão em disputa somente as condições materiais de sobrevivência, o estão também as condições simbólicas, compostas por diversas argumentações, de diferentes naturezas.

Classe e consciência de classe são sempre o último e não o primeiro degrau de um processo histórico real. Mas se adotarmos uma concepção estática da categoria de classe, ou se fizermos descender esse nosso conceito de um modelo teórico preliminar de totalidade estrutural, não procederemos assim, pois estaremos subentendendo que a classe está presente desde o início como um resultado de relações de produção. (THOMPSON, 2012, p. 274).

Ao afirmarmos que classe e consciência de classe são sempre a última fase de um processo real, naturalmente não pensamos que isso seja tomado no sentido literal e mecânico. Uma vez que se tem uma consciência de classe desenvolvida, xs jovens podem ser "socializadxs", em um sentido classista, e as instituições de classe prolongam as condições de sua formação. Podem-se gerar tradições ou costumes de antagonismos de classe que não correspondam mais a um antagonismo de interesses. Mas, tudo isso faz parte da complexidade que habitualmente encontramos na nossa análise histórica, especialmente na 
contemporânea. A questão é que não podemos falar de classes sem que as pessoas, diante de outros grupos, por meio de um processo de luta (o que compreende uma luta em nível cultural), entrem em relação e em oposição sob uma forma classista; ou, ainda, sem que modifiquem as relações de classe herdadas, já existentes (THOMPSON, 2012).

A opção de Thompson (2012) de romper com a tradição marxista ortodoxa, que coloca em oposição a base e a superestrutura, é fundamental para o argumento que defendemos neste trabalho. Não é possível entender o conservadorismo desvinculando-o dos interesses de classe, mas não é só isso. O conservadorismo é reproduzido como argumento de uma retórica que ultrapassa as questões de classe, encontrando os motes abstratos de sobrevivência que estão em disputa no campo da cultura, em especial nas diferentes demandas dos grupos minoritários: mulheres, lésbicas, gays, negrxs etc. Isso não quer dizer que a luta de classes desapareça. Ela simplesmente se torna mais complexa, com mais variantes ocorrendo em diversos espaços sociais.

Mas, ainda fica a dúvida sobre o que é o conservadorismo. Já entendemos que ele se dá a partir de uma retórica e que esta se efetiva no campo da cultura. Porém, de que forma? Segundo Mannheim (1959, p. 79), “o pensamento humano se desenvolve em 'estilos’ e há diferentes escolas de pensamento distinguíveis pelos diferentes modos como utilizam diferentes padrões e categorias de pensamento”. Há importância em se compreender como se forma o estilo do pensamento conservador, pois herdamos a crença filosófica de que o pensamento não se desenvolve como uma parte, como uma parcela do processo histórico, mas que se enraíza na sociedade como natureza de um ente absoluto; ou que, de acordo com xs historiadorxs literários, o pensamento humano é fruto da personalidade do indivíduo. Primeiramente, isso faz com que a história do pensamento pareça artificialmente homogênea e indiscriminada. É devido a essa falta de interesse no nível intermediário que nossas ferramentas para distinguir estilos de pensamento não estão desenvolvidas. Nós não notamos diferenças vitais entre estilos de pensamento porque não acreditamos em sua existência. Se nós nos esforçássemos em perceber as inúmeras e leves mudanças no desenvolvimento do modo de pensar de um grupo, através de sua história, a homogeneidade artificialmente imposta ou a atomização indiscriminada dariam lugar a uma diferenciação mais apropriada dos modos de pensar (MANNHEIM, 1959, p. 80).

O problema, então, do discurso conservador é seu poder de persuasão. Como bem analisa Mannhein (1959), o conservadorismo nasce do tradicionalismo; portanto, tem um forte significado social e identitário, tornando mais fácil, para uma parcela da população, se identificar com seu discurso. Isso potencializa a já mencionada carga emotiva do termo. E tal potencialização impulsiona a organização de grupos proativos em defesa da "moral e dos bons costumes”, muito em voga atualmente no país e no mundo.

A análise de Mannhein (1959) tem limites. Apesar de entender o conservadorismo como um processo histórico, ele o faz nos limites daquilo que se convencionou chamar de sociologia do conhecimento. Nesse processo, em seu livro Ideologia e utopia (MANNHEIN, 1972), ele acabou reduzindo sua análise a duas possibilidades: ideologia (conservadora) e utopia (transformadora). Nesse sentido, seguindo o caminho de análise de Michael Löwy 
(1991), entendemos que o conservadorismo tem características que vão além da sociologia do conhecimento.

Löwy e Sayre (2015), em seu livro Revolta e melancolia, fazem uma profunda análise sobre o romantismo, entendendo que os conceitos são construídos historicamente e variam de acordo com as demandas históricas, regionais e políticas de cada período, variando de intensidade e posições, marcando-se por contradições e tensões que não são possíveis de serem reduzidas a perspectivas simplistas. É dessa forma que começamos a entender o conservadorismo.

Tendo em vista o que foi exposto até aqui, compreendemos o conservadorismo como uma das múltiplas e poderosas narrativas, retóricas e discursos que compõem o universo da cultura. Vamos tentar entender um pouco mais o conceito de cultura. Raymond Williams (2011) afirma que, nas últimas décadas do século XVIII e na primeira metade do século XIX, o conceito ganhou força e adquiriu novos significados. Ainda segundo o mencionado autor, foi a revolução industrial que impulsionou novos caminhos para a linguagem e, nisso, algumas palavras emergiram com destaque: indústria, democracia, classe, arte e cultura. Todas essas palavras e aquilo que elas representam se desenvolveram de forma interligada.

A importância dessas palavras, na nossa estrutura moderna de significados, é óbvia. As mudanças em seu uso, naquele período crítico, revelam uma mudança geral nas nossas maneiras características de pensar sobre nossa vida em comum: sobre nossas instituições sociais, políticas e econômicas; sobre os objetivos que essas instituições são destinadas a representar; e sobre as relações com essas instituições e os objetivos de nossas atividades no aprendizado, na educação e nas artes. (WILLIAMS, 2011, p. 15).

Neste trabalho, nos dedicaremos exclusivamente ao termo cultura. Williams (2011, p. 19-20), em suas pesquisas, deseja mostrar a emergência da cultura como uma abstração e um absoluto: uma emergência que, de uma maneira muito complexa, funde duas respostas gerais:

[...] primeiro, o reconhecimento da separação prática de certas atividades morais e intelectuais do ímpeto propulsor de um novo tipo de sociedade; segundo a ênfase dessas atividades, como um tribunal de recursos, deve ser estabelecida por sobre os processos de juízo social prático e ainda assim se oferecer como alternativa mitigadora e arregimentadora.

Dessa forma, o novo uso do conceito de cultura não foi uma mera reação à nova indústria, que modificava substancialmente o estilo de vida das pessoas; mas, foi também uma reação às novas propostas de sociedade, que se manifestavam no período, principalmente aos novos desenvolvimentos políticos e sociais, à democracia. Tendo em vista o contexto da emergência do conceito, a ideia de cultura parece vinculada à defesa de uma tradição com impacto nas manifestações artísticas e até mesmo nas posições políticas da sociedade. Com o desenvolvimento histórico do conceito de cultura, seu significado foi se modificando até o formato como o entendemos hoje. Seguindo ainda Williams (2011, p. 18), antes da 
Revolução Industrial, cultura significava, primordialmente, a "tendência a crescimento natural”. Esse último uso, que seria uma cultura de algo, se transformou, no século XIX, em cultura como tal, uma coisa em si mesma.

Veio a significar, primeiramente, 'um estado geral ou hábito da mente', tendo relações muito próximas com a perfeição humana. Segundo, passou a significar 'uma situação geral de desenvolvimento intelectual em uma sociedade como um todo'. Terceiro, passou a significar o 'corpo geral das artes'. E quarto, já mais tarde nesse mesmo século, passou a significar 'todo um modo de vida, material, intelectual e espiritual'. Como bem sabemos, veio também a ser uma palavra que muitas vezes provocava hostilidade ou constrangimento. (WILLIAMS, 2011, p. 18).

Portanto, o conceito de cultura se desenvolveu no mesmo período em que a retórica conservadora se manifestou com força. Todavia, entendemos o conceito de cultura como um lócus de disputa atravessado pela luta de classes, onde são desenvolvidas múltiplas narrativas e explicações sobre o homem, a sociedade e o mundo. O conservadorismo é somente uma dessas narrativas, que se organiza para naturalizar as desigualdades sociais. Por isso, tal narrativa vai para além da questão de classe; ela se manifesta também naturalizando a desigualdade de raças, gêneros, sexualidades e religiões.

O conservadorismo se caracterizou então por um discurso contrário a ganhos e direitos sociais; se sustenta na anti-intelectualidade, na antirracionalidade, na luta contra qualquer forma de revolução e contra a democracia, tornando-se uma forte narrativa em disputa no campo da cultura.

Uma vez desenvolvido o que estamos entendendo por conservadorismo, passamos agora a ver como tal narrativa se expressa e difunde no campo educacional, reproduzindo as desigualdades sociais, tendo em vista duas temáticas: uma referente aos discursos religiosos e outra referente aos discursos sobre gêneros, buscando, assim, apresentar elementos que possam contribuir para a compreensão e os perigos do conservadorismo para a educação brasileira.

\section{Conservadorismo e currículo}

As disputas na cultura atravessam todos os campos sociais e são objetos de interesse especial para a educação, uma vez que as demandas dos diferentes grupos estão encontrando respaldo no campo político, exigindo uma política educacional adequada às suas conquistas. Todavia, vivemos tempos conservadores e muitas conquistas e lutas acham-se em pleno ataque desses grupos. Para refletirmos um pouco sobre tais ataques à escola pública, escolhemos dois temas candentes: o Ensino Religioso na $\mathrm{BNCC}^{3}$ e a "ideologia de gênero" 4 . 
A discussão sobre a disciplina Ensino Religioso nas escolas públicas é muito polêmica e desperta paixões. Principalmente pelo fato de que tal discussão invisibiliza o debate mais importante, o da laicidade do Estado. Mas, afinal, o que é um Estado laico?

Na base de sustentação da sociedade democrática que emerge após a Revolução Francesa, a laicidade era um dos pilares mais importantes. Todavia, assim como o próprio conceito de democracia, o conceito de laicidade do Estado é um conceito em processo. Por séculos, os Estados, especialmente os europeus, estruturavam sua legitimidade por determinação do sagrado, de modo que $\mathrm{x}$ chefe de Estado era consideradx umx representante de Deus na terra. $X$ estadista reinava por direito divino, ou seja, em tese elx recebia o poder político da própria divindade. Por isso, o poder dx governante era considerado sagrado, tirando daí sua legitimidade, que se espraiava por todo o Estado. Com essa base religiosa, o Estado privilegiava uma religião em detrimento de outras.

O Estado torna-se laico quando prescinde da religião para garantir sua legitimidade, definida exclusivamente pela soberania popular. Quando o Estado dispensa a religião como elemento de coesão social e de unificação nacional, ele torna-se um Estado laico (BLANCARTE, 2008).

Primeiramente, ressaltamos que o Estado laico é imparcial em matéria de religião, ou seja, ele não interfere nos conflitos ou nas alianças entre as organizações religiosas ou mesmo na atuação dxs não crentes. O Estado laico respeita, então, todas as crenças religiosas, desde que não atentem contra a ordem pública; assim como respeita a não crença religiosa. Dessa forma, o Estado laico não é neutro, pois atua na defesa dos indivíduos e na garantia da liberdade de crença e não crença, fazendo uso dos mecanismos necessários e legais para efetivar tal garantia.

Outro resultado da laicidade do Estado é que a moral é coletiva - particularmente, a que é sancionada pelas leis deixa de ter caráter sagrado, isto é, deixa de ser tutelada pela religião, passando a ser definida no âmbito da soberania popular (CUNHA, 2018). Isso quer dizer que as leis, inclusive as que têm implicações éticas ou morais, são elaboradas com a participação de todxs - dxs crentes e dxs não crentes (SEPULVEDA; SEPULVEDA; FERNANDES, 2015). O Estado laico não pode admitir imposições de instituições religiosas para que tal ou qual lei seja aprovada ou vetada, nem que alguma política pública seja mudada por causa de valores religiosos. Mas, ao mesmo tempo, o Estado laico não pode desconhecer que xs religiosxs de todas as crenças têm o direito de influenciar a ordem política, fazendo valer, tanto quanto xs não crentes, sua própria versão sobre o que é melhor para toda a sociedade (CUNHA, 2016).

Muitxs autorxs entendem que a disciplina escolar Ensino Religioso fere a laicidade do Estado. Sepulveda e Sepulveda (2017) defendem que a simples existência de Ensino Religioso como disciplina ministrada na escola é uma forma de se manter a religião como um elemento da formação da sociedade, não levando em conta que tal disciplina interfere na decisão individual de se ter ou não religião, dando uma atribuição à escola pública que não é de sua incumbência.

Muitxs defensorxs do Ensino Religioso como disciplina escolar entendem que se essa disciplina for dada de forma interdisciplinar, ecumênica, não estaria ferindo o princípio da 
laicidade. Dissentimos dessa posição quanto a dois fatores. O primeiro diz respeito à impossibilidade de se ministrar conhecimentos referentes a todas as religiões. O que acaba ocorrendo é um ensino ligado à matriz cristã e suas diferentes denominações (FERNANDES, 2014). O segundo fator é que a religião é uma manifestação de foro íntimo, do mundo do privado, na qual se acredita baseando-se em fé. A escola pública é o lugar das diferenças, das dúvidas, dos debates; não tem espaço para uma disciplina que se estrutura em dogmas que não admitem debates. A existência de Ensino Religioso como disciplina escolar corrompe a função da escola. Até porque a religião já está na escola. As pessoas são religiosas e elas não deixam suas religiões em casa e vão trabalhar. Assim, a função da escola democrática e laica é construir conhecimentos capazes de estimular o respeito às diferenças, inclusive à religiosa (SEPULVEDA; SEPULVEDA, 2017), com as pessoas religiosas aprendendo a conviver com adeptos de outras religiões, com os diferentes, sem preconceito. Isso só é possível em uma escola pública laica, que não impõe nenhuma religião, garantindo a todxs o direito democrático de estudar em um lugar acolhedor.

Dessa forma, se uma escola democrática precisa ser laica, isso significa ela não oferecer uma disciplina de Ensino Religioso. Todavia, não significa que a religião não possa ser discutida na escola como um conteúdo a ser debatido pelas diferentes disciplinas escolares. O que seria da aula de História do Brasil sem a menção aos jesuítas? Como respeitar a cultura africana e fazer valer a lei n. 10.639/2003 sem as religiões de matrizes africanas (Brasil, 2003)? Isso pode ser feito sem que se precise ensinar dogmas religiosos.

Feita essa reflexão, fica difícil entender a inserção da disciplina escolar Ensino Religioso na BNCC. Só é possível entendê-la a partir do discurso conservador articulado com o poder político. Grupos religiosos, bancadas religiosas nas Assembleias e Câmaras no Brasil inteiro se organizaram para a defesa de inclusão de tal disciplina no currículo. O conservadorismo ganha força, como já foi dito, no tradicionalismo. E a tradição católica na cultura brasileira reforça argumentos conservadores. Isso não significa que todxs xs católicxs são conservadorxs, até porque entendemos a religião como um problema de foro íntimo. Todavia, a presença da religião no tecido político-social, especialmente, da católica, mas não somente no seio da escola, é uma realidade histórica efetiva (CUNHA, 2016).

Para se entender melhor o problema da presença religiosa na BNCC, mostrando a forte atuação do discurso conservador na redação final daquele documento, entendemos ser necessário um aprofundamento histórico do seu desenvolvimento.

No dia 3 de junho de 2014, o Ministério da Educação (MEC) recebeu oficialmente a primeira versão do documento orientador para a discussão nacional sobre a BNCC, que definia as áreas fundamentais para a formação dxs alunxs. Naquele momento, o MEC deixou claro que aquele documento fora produzido e seria debatido pelxs agentes do campo educacional. A preocupação de um currículo comum no Brasil não é novidade e ainda está presente no cenário educacional brasileiro.

Em 20 de dezembro de 1996, a lei n. 9.394, conhecida como Lei de Diretrizes e Bases da Educação Nacional (LDBN), foi promulgada, e no seu art. 26 já se mencionava que os currículos do ensino fundamental e médio deveriam ter uma base nacional comum. 
Art. 26. Os currículos do ensino fundamental e médio devem ter uma base nacional comum, a ser complementada, em cada sistema de ensino e estabelecimento escolar, por uma parte diversificada, exigida pelas características regionais e locais da sociedade, da cultura, da economia e da clientela. (BRASIL, 1996).

Para atender à determinação do art. 26 da LDBN, o MEC promulgou a Resolução n. 4, de 13 de julho de 2010, que definiu as Diretrizes Curriculares Nacionais para a Educação Básica. Nessa resolução, encontramos novamente a preocupação com uma formação básica comum nacional (Brasil, 2010).

O art. 26 da lei n. 9.394/1996 foi modificado por uma nova redação dada pela Lei n. 12.796/2013, lei essa que dispõe sobre a formação dxs profissionais da educação e dá outras providências.

Art. 26. Os currículos da educação infantil, do ensino fundamental e do ensino médio devem ter base nacional comum, a ser complementada, em cada sistema de ensino e em cada estabelecimento escolar, por uma parte diversificada, exigida pelas características regionais e locais da sociedade, da cultura, da economia e dos educandos. (BRASIL, 1996, 2013a).

Já em 2013 o MEC lançou as Diretrizes Curriculares Nacionais da Educação.

Nesta publicação, estão reunidas as novas Diretrizes Curriculares Nacionais para a Educação Básica. São estas diretrizes que estabelecem a base nacional comum, responsável por orientar a organização, articulação, o desenvolvimento e a avaliação das propostas pedagógicas de todas as redes de ensino brasileiras. (BRASIL, 2013b).

Após a elaboração, pelo MEC, da primeira versão do documento orientador para a discussão nacional sobre a BNCC, o mencionado ministério abriu, a partir de agosto de 2014, uma consulta aos estados, ao Distrito Federal e aos municípios sobre os documentos e normas curriculares produzidos pelos sistemas de educação desde 2010. O objetivo dessa iniciativa era produzir um estudo que subsidiasse as discussões em torno da BNCC. Também foram realizadas, pelo MEC, reuniões com especialistas de universidades e professorxs da educação básica das diferentes áreas do conhecimento, para auxiliar no debate sobre a BNCC.

A elaboração da primeira versão da BNCC foi realizada entre fevereiro de 2014 a janeiro de 2015, durante o mandato de Henrique Paim no MEC. O início da consulta sobre o texto da primeira versão da BNCC se deu a partir de agosto de 2014. Durante a consulta de tal documento, Cid Gomes assumiu o ministério, porém não chegou a ficar dois meses no cargo. Em seguida, foi substituído por Renato Janine Ribeiro, que ficou na pasta de abril a outubro de 2015. Durante o seu mandato, a consulta continuou sendo feita, porém os textos produzidos foram alvo de muitas críticas, segundo a própria comunidade acadêmica (LOPES, 2015; PEREIRA; COSTA; CUNHA, 2015). 
Posteriormente, Renato Janine Ribeiro foi substituído por Aloizio Mercadante, que ficou à frente do MEC de outubro de 2015 a maio de 2016. Em seu mandato, Mercadante também manteve a consulta sobre o documento da BNCC.

Nessa versão, houve a realização de um colóquio nacional denominado "A Base em Questão: desafios para a educação e o ensino no Brasil” realizado no dia 25 de abril de 2016, no Rio de Janeiro. Nesse colóquio, a ANPEd posicionou-se contra a metodologia utilizada pelo MEC que adotou a consulta virtual em detrimento dos debates públicos e, ainda, a pouca participação dos docentes nesse processo. (SILVA; SANTOS, 2018, p. 4).

No início do mês de maio de 2016, ainda à frente da pasta, o ministro Aloizio Mercadante entregou a segunda versão da BNCC ao Conselho Nacional de Educação (CNE). Contudo, após o impedimento da presidenta Dilma Rousseff, em 2016, a segunda versão da BNCC foi retirada do CNE.

Num novo contexto, no governo do presidente Michel Temer, até então vice de Dilma Rousseff, a questão da BNCC ganhou novos contornos. O ministro da Educação, José Mendonça Bezerra Filho, que assumiu a pasta em 12 de maio de 2016, retirou a segunda versão da BNCC da avaliação do CNE, sob a alegação de que o documento ainda não estava pronto e precisava ser mais bem discutido. Naquele momento, a consulta axs especialistas foi suspensa e o debate, interrompido.

No dia 4 de abril de 2017, o MEC enviou para a imprensa a terceira versão da BNCC, na qual constavam os termos gênero e orientação sexual. Contudo, no dia 6 de abril de 2017, tais termos foram descartados, quando foi entregue outra versão da BNCC ao CNE (BRASIL, 2017; CANCIAN, 2017). Assim, o MEC foi alvo de várias críticas, por exemplo dos movimentos de lésbicas, gays, bissexuais, travestis, transexuais, transgênerxs, intersexos, simpatizantes $^{5}$ (LGBTIS+), motivadas pela retirada das expressões gênero e orientação sexual do documento.

Atribui-se a retirada desses termos às pressões do Movimento Escola Sem partido $^{6}$, que possui representantes da Frente Parlamentar Evangélica. Para a secretária executiva do MEC, Maria Helena Castro, a retirada dos termos foi uma maneira de "evitar redundância e que não comprometeria ou modificaria os pressupostos da BNCC”. (SILVA; SANTOS, 2018, p. 5).

Vamos agora dar um exemplo de como foram as modificações feitas, no que se refere às questões de gênero, tendo como foco um ponto da BNCC. Na unidade temática "Vida e evolução", no eixo "Vida e sexualidade", previsto para o ensino de Ciências do $8^{\circ}$ ano do ensino fundamental, o documento anterior elencava, entre as "habilidades" a serem desenvolvidas nos alunos, a capacidade de

Selecionar argumentos que evidenciem as múltiplas dimensões da sexualidade humana (biológica, sociocultural, afetiva e ética) e a necessidade de respeitar, 
valorizar e acolher a diversidade de indivíduos, sem preconceitos baseados nas diferenças de sexo, de identidade de gênero e de orientação sexual. (BRASIL, [2017] apud CANCIAN, 2017).

As referências a "identidade de gênero" e “orientação sexual”, logo, foram aquelas suprimidas na versão final do documento. Isso se deu em virtude da pressão política da bancada religiosa (BRASIL, 2017; CANCIAN, 2017).

Após a publicação oficial da terceira versão, as críticas dos grupos de evangélicxs e católicxs conservadorxs continuaram sendo desenvolvidas; por isso, mais alterações foram feitas na BNCC, para atender aos interesses desses grupos.

As críticas do grupo à terceira versão da BNCC podem ser acompanhadas em diferentes mídias: reportagens de jornal, entrevistas em rádio, vídeo de audiências públicas, postagens no citado blog e nos documentos produzidos que foram disponibilizados também no Blog. Na postagem "A $3^{\mathrm{a}}$ versão da BNCC: análise e constatações (nota técnica)” (SILVA; PETINNELI, 2018), dedicada à uma análise dos conteúdos da Base Nacional Comum Curricular para a Educação Infantil e o Ensino Fundamental, os autores começam o texto apresentando o histórico da construção da BNCC, relembrando a pressão exercida pela bancada cristã e grupos conservadores para a retirada de todas as menções a gênero do documento. Entretanto, defendem a ideia de que a ameaça da "Ideologia de Gênero” ainda estaria presente no documento. (MOURA, 2018, p. 58).

Ainda segundo Moura (2018), foram tantas as modificações feitas sobre a terceira versão que é possível se falar em uma quarta versão do documento. Foi justamente no governo Temer que o discurso conservador tomou conta da BNCC. O texto foi praticamente todo refeito pelas bancadas religiosas, que chegaram a propor um documento alternativo.

Esta versão alternativa da BNCC teria sido subscrita pela Frente Parlamentar Evangélica, pela Frente Parlamentar Católica, pela Frente Parlamentar Mista em defesa da Vida e da Família da Câmara e do Senado e pela Frente Parlamentar em defesa da Vida e da Família da Câmara dos deputados e teria sido entregue em 25 de outubro de 2017 aos deputados e senadores e diretamente ao Ministro Mendonça Filho e ao CNE. (MOURA, 2018, p. 55).

Dessa forma, o conservadorismo político de base religiosa trabalha com a tese de que as homossexualidades vão destruir a família, disseminando o medo pela sociedade. Há de se considerar que esse discurso é muito bem elaborado, pois, em alguns casos, sua construção está revestida de ideias progressistas. Vejamos o caso do termo gênero ou da expressão teorias de gênero, transformados em ideologia de gênero. As teorias de gênero são aquelas que entendem o gênero como uma manifestação do indivíduo na sociedade, ou seja, como o indivíduo manifesta sua performance de gênero (BUTLER, 2017). Essa expressão foi apropriada e modificada pelo pensamento conservador para designar uma pretensa prática escolar de ensinar que as crianças e xs jovens podem desenvolver qualquer identidade de 
gênero, independentemente de sua identidade sexual. Ou seja, o que xs conservadorxs dizem é que a escola está ensinando xs alunxs a serem lésbicas e gays.

Desde 2014, período da discussão e aprovação do atual Plano Nacional de Educação, o Escola sem Partido e as bancadas religiosas propuseram projetos de lei que estão sendo apresentados, nos estados e municípios, com nomes variados, mas com os mesmos objetivos. Segundo Moura (2018), em postagem feita pela página virtual do movimento, intitulada Orientações para uma leitura conservadora da BNCC, assinada por Silva (2018), xs conservadorxs cristões alertaram sobre o "perigo" da BNCC.

Desde o início, a BNCC despertou a preocupação da parte conservadora de professores e pesquisadores cristãos evangélicos e católicos. De um lado, uma parte, pequena, pouco expressiva, voluntária e independente política e institucionalmente, dedicou se a estudar e alertar os cristãos acerca dos riscos e embaraços que o documento representa para o futuro da hegemonia cristã brasileira. (MOURA, 2018, p. 56).

Ressaltamos que, se a BNCC foi defenestrada do jeito que foi, os ataques a propostas curriculares mais progressistas existentes nos estados e municípios foram bem mais fortes e efetivos. A educação brasileira, sobretudo em sua política curricular, está vivendo um momento crítico, correndo riscos enormes de retrocesso, afetando principalmente os grupos identitários que mais sofrem violência no país hoje.

A terceira versão da BNCC (BRASIL, 2017) absorveu bastante do pensamento conservador religioso, das propostas do movimento Escola sem Partido e de grupos empresariais. Essa versão final da BNCC também recebeu críticas fortes de uma boa parte da academia (MACEDO, 2017; CUNHA, 2016). Primeiro, pelo seu caráter aligeirado; segundo, pela falta de diálogo, em sua concepção, com a comunidade educacional; e, também, pelo seu caráter impositivo. Macedo (2017) argumenta que tal modelo curricular articula propostas neoliberais com discursos conservadores, em especial os do movimento Escola sem Partido.

Meu argumento é o de que a definição de uma BNCC é parte do funcionamento de uma normatividade neoliberal entendida como "uma forma peculiar de razão que configura todos os aspectos da existência em termos econômicos” (BROWN, 2015, p. 17). Entendo que a entrada em cena das demandas conservadoras do ESP desloca ainda mais o jogo político no sentido do controle que exclui a diferença, ao mesmo tempo em que torna explícita essa exclusão. Guia minha argumentação o compromisso com a defesa de que educação e currículo estão diretamente imbricados com a diferença como tal, assim como das conquistas — poucas ainda - dos diferentes grupos sociais que lutam por representação na esfera pública. (MACEDO, 2017, p. 509-510).

Seguindo o raciocínio de Macedo (2017), essa proposta curricular atende, além dos grupos conservadores religiosos, a interesses dos novos grupos empresariais ${ }^{7}$ que disputam 
o controle educacional e que para isso precisavam que se adequasse a estrutura educacional às suas demandas de mercado. Com isso, dissimuladamente, tais grupos exploraram uma suposta crise das escolas públicas, na prática e no discurso, para favorecer seus interesses.

É nesse contexto complexo e carregado de interesses privados que se insere a questão da disciplina de Ensino Religioso na BNCC (BRASIL, 2017), assim como a privação da abordagem da questão de gênero. A força dita reacionária, nesse contexto, mostrou-se tão grande que, segundo Cunha (2016), foi a primeira vez na história da educação brasileira que a disciplina de Ensino Religioso tornou-se um componente do campo das ciências humanas.

Num movimento de promoção simbólica, o ER [a disciplina de Ensino Religioso] encontra-se localizado junto à área de Ciências Humanas, também dito como integrado a ela. A integração resultaria das conexões existentes com as especificidades da História, da Geografia, da Sociologia e da Filosofia, “de modo a estabelecer e a ampliar diálogos e abordagens teórico-metodológicas que transcendem as fronteiras disciplinares” (BRASIL, 2015b, p. 281). Essa genérica declaração de intenção desconhece as grandes diferenças entre as abordagens teórico-metodológicas dessas disciplinas. A despeito de suas especificidades, a Filosofia e as Ciências Sociais (digamos Humanas), vale para todas elas o princípio do agnosticismo metodológico, que é justamente o contrário do que pretende a proposta com o ER. Não bastasse isso, as teorias de cada uma delas abordam a religião distintamente, entre si e da BNCC. (CUNHA, 2016, p. 276).

A forma inédita de tratamento dispensado pela BNCC (BRASIL, 2017) à disciplina de Ensino Religioso demonstra o quanto o discurso conservador avançou, na estrutura escolar. Como já foi dito, nós entendemos que a existência de tal disciplina fere o princípio da laicidade do Estado. Entretanto, há aí um agravante, pois aquilo que era, até então, uma atribuição dos estados e municípios - organizar um currículo com a disciplina de Ensino Religioso - passa agora a ser definido nacionalmente. Com isso, afronta-se ainda mais o problema da liberdade de crença nas escolas públicas e a própria manutenção da laicidade, que, como dissemos, é um importante pilar da democracia.

Mas, por que a absorção da disciplina de Ensino Religioso pela BNCC (BRASIL, 2017) agrava o problema da liberdade de crença? O Estado laico é aquele que defende a liberdade de crença e não crença, ou seja: ao se definir a matéria de Ensino Religioso como disciplina do campo das ciências humanas, ela é transmitida como se seu teor contemplasse um conteúdo científico. Isso fortalece o discurso religioso nas escolas e aumenta as tensões entre conhecimentos que são contrastantes, muitas vezes antagônicos.

Vamos exemplificar esse problema por meio de uma tensão complexa existente no conteúdo de Ciências: evolucionismo e criacionismo (DORVILLÉ; SELLES, 2016). O criacionismo é um argumento de fé, sobre o qual não existe nenhuma sustentação científica. Todavia, ao se dispor a disciplina de Ensino Religioso no campo das ciências humanas, ela ganha estatuto de cientificidade, podendo potencializar o discurso religioso de forma a colocar em xeque a própria ideia do evolucionismo. 
Seguindo o mesmo raciocínio, se nos aprofundarmos na própria proposta curricular e de conteúdos de Ensino Religioso, veremos muitas contradições que irão dificultar bastante a vida de professorxs nas escolas públicas brasileiras. Essxs, por sua vez, são os que mais precisam de apoio no que concerne à laicidade, pois muitas vezes não conseguem conciliar sua função docente com suas crenças religiosas pessoais, gerando confrontos com estudantes que não compartilham de sua visão pessoal.

Mais do que os alunos, os professores é que precisam ser educados sobre como agir numa escola pública: não impor suas próprias crenças (como se fossem universais) e respeitar diferenças entre as religiões e entre os religiosos e os não religiosos. Essa é a grande tarefa, mais ligada ao currículo oculto do que ao manifesto. Ódio e discriminação não são dirigidos somente aos adeptos das diferentes religiões. Tampouco é religiosa sua solução. A BNCC esteve tão preocupada com a avaliação dos alunos que esqueceu que os professores constituem elemento essencial do currículo. (CUNHA, 2016, p. 282).

Em suma, a incorporação da disciplina de Ensino Religioso na BNCC (BRASIL, 2017) comprometeu a laicidade do Estado e da escola pública. Vale ressaltar que isso aconteceu num período de plena ascensão conservadora no Brasil, com reflexos reais no campo educacional. Tal debate ocorreu de forma concomitante com os referentes à questão dos gêneros, impulsionados ambos pelo movimento Escola sem Partido.

\section{O movimento Escola sem Partido e sua influência numa instituição educacional}

Para entendermos melhor o que é o Escola sem Partido, faremos agora uma pequena reflexão sobre ele. Tal movimento, surgido em 2004, chegou até a academia brasileira como uma piada. Poucos foram os intelectuais que dimensionaram o perigo de tal proposta, conforme argumenta Penna (2017, p. 36):

Outra reação igualmente comum é não levar a sério a ameaça apresentada por esse discurso e os projetos de lei que incorporam suas ideias por ser algo que, para nós, é muito obviamente contraditório com a legislação educacional existente. O discurso do Escola sem Partido não foi devidamente enfrentado, a meu ver, desde o momento em que ele surgiu, em 2004, justamente por parecer absurdo e sem fundamentos legais para aqueles que conhecem o debate educacional, e também porque ele se espalha com muita força, não em debates acadêmicos, mas nas redes sociais. Esse discurso utiliza-se de uma linguagem próxima a do senso comum, recorrendo a dicotomias simplistas que reduzem questões complexas a falsas alternativas e valendo-se de polarizações já existentes no campo político para introduzi-las e reforçá-las no campo educacional. 
Todavia, é necessário enfatizar que o discurso produzido pelo Escola sem Partido ganhou uma oxigenação que lhe deu novas forças, de parte de uma determinada narrativa religiosa: o combate à “ideologia de gênero”. Tal oxigenação despertou a preocupação de intelectuais progressistas que, finalmente, passaram a analisar o movimento (FRIGOTTO, 2017).

A narrativa do Escola sem Partido se estrutura a partir da premissa de que xs professorxs das escolas são doutrinadorxs que impõem uma visão única de mundo - que seria a comunista. Tal retórica é resultado de um projeto conservador que culpabiliza a esquerda brasileira por tudo que consideram negativo na sociedade brasileira, em especial o Partido dos Trabalhadores (PT), alegando que tal partido se baseia e propaga o que eles denominam marxismo cultural. Este seria a efetivação das propostas teóricas do autor marxista italiano Antonio Gramsci, que, segundo o Escola sem Partido, defendia a ocupação cultural da sociedade, via preenchimento de cargos na administração pública, principalmente na área da educação. Segundo Moura (2018), em um artigo publicado na página do Escola sem Partido, intitulado Livros didáticos para a revolução socialista bolivariana (SILVA, [201-]), fica clara a visão conservadora do movimento.

Está em curso, pois, em nosso sistema de ensino público o plantio da semente revolucionária socialista inspirada em Gramsci para uma revolução que se pretende pacífica, caso não haja acidente de percurso. Para o cumprimento deste objetivo, trabalha-se na sociedade a construção hegemônica do ideal comunista por meio de estratégias discursivas que possibilitem a subjetivação dos sujeitos. (SILVA, [201-]).

Sendo assim, os defensores do Escola sem Partido iniciaram uma forte campanha contra as escolas e universidades, acusando xs professorxs de serem “doutrinadores” e xs ameaçando. A geração de medo passou a ser sua principal arma. Novos inimigos emergem, desse processo: os movimentos identitários, em especial aqueles que defendem pautas feministas e LGBTIS+.

A narrativa do Escola sem Partido, vitaminada pelo discurso religioso, encontrou abrigo político na família Bolsonaro, que encomendou ao procurador do estado de São Paulo, Miguel Nagib - não por acaso, coordenador daquele movimento -, um modelo de projeto de lei com base nos argumentos do Escola sem Partido, no intuito de ser apresentado para políticos, estimulando-os a construir projetos similares em todos os entes federados.

Com isso, o resultado mais efetivo foi o ataque e a caça aos projetos de lei que defendessem de alguma forma as pautas de gênero. Foi essa onda de ataques que atingiu em cheio a BNCC (BRASIL, 2017), por exemplo. O clima tenso na política e na economia brasileira - 12 milhões é o número de desempregadxs em 2019 (Loschi, 2019) - afetaram a sociedade de tal forma que o discurso conservador passou a ocupar um lugar de destaque. A culminância disso foi a eleição de Jair Bolsonaro à presidência do Brasil, em 2018. Seu discurso de que não permitiria que se fizesse "ideologia de gêneros" nas escolas, entre outras pautas conservadores, adentrou em cheio algumas dessas instituições. 
Fornecemos agora um exemplo da inserção do discurso presidencial conservador em uma escola pública no estado do Rio de Janeiro. Em pesquisa que desenvolvíamos desde 2015, verificamos o aumento do medo, como fruto do discurso ameaçador de Jair Bolsonaro; o que impactou a nossa investigação, pois foi percebida a resistência, por parte da direção da escola, ao desenvolvimento de palestras sobre o combate à gayfobia ${ }^{8}$ e à lesbofobia ${ }^{9}$, o que não ocorria quando o projeto de pesquisa foi implementado, uma vez que a diretora e duas coordenadoras o autorizaram e se mostraram bem solícitas quanto ao desenvolvimento de palestras, por pesquisadores da temática, e à apresentação de conteúdos expositivos por parte de grupos de militância LGBTIS+.

Contudo, aquela solicitude inicial se revelou, então, que estava relacionada às expectativas da direção e da coordenação da escola quanto ao controle dos comportamentos dessxs estudantes, já que foi alegado que tais alunxs eram muito violentxs, pois usavam faixas nas cabeças com as palavras escritas “eu sou viado”. As faixas usadas pelos discentes não nos soavam a atos violentos, mas nos davam indícios de serem táticas de sobrevivência para modificar as regras e as relações de poder em voga na instituição escolar.

As maneiras de fazer, os estilos de ação dos sujeitos reais obedecem a outras regras que não aquelas da produção e do consumo oficiais; eles criam um jogo mediante a estratificação de funcionamento dos diferentes e interferentes, dando origem a novas maneiras de utilizar a ordem imposta. Para além do consumo puro e simples, os praticantes desses novos modos de lidar com a ordem desenvolvem ações, fabricam formas alternativas de uso, tornando-se produtores/autores, disseminando alternativas, manipulando, ao seu modo, os produtos e regras, mesmo que de modo invisível e marginal (OLIVEIRA, 2008, p. 56). Como diz Certeau (2001, p. 47), essas táticas são gestadas em "maneiras de fazer” que se constituem em:

[...] vitórias do "fraco" sobre o mais "forte" (os poderosos, a doença, a violência das coisas ou de uma ordem, etc.), pequenos sucessos, artes de dar golpes, astúcias de "caçadores", [...] simulações polimorfas, achados que provocam euforia, tanto poéticos quanto bélicos. [...] Essas táticas manifestam igualmente a que ponto a inteligência é indissociável dos combates e dos prazeres cotidianos que articula.

À medida que a direção e a coordenação escolar foram percebendo que nossa pesquisa não tinha como propósito controlar ou adestrar o comportamento de tais estudantes, elas foram deixando de ser tão disponíveis para com a nossa presença na instituição. Levantamos como pista que a mudança da aceitabilidade da direção e da coordenação da escola para com a nossa pesquisa podia estar associada ao crescimento de projetos conservadores na sociedade brasileira (CORRÊA, 2019).

Para o conservadorismo, o papel da educação é central para a questão social, pois por meio dela se pode empreender uma reforma moral da sociedade, a ponto de se permitir a internalização de uma moralidade pelos indivíduos, moralidade essa necessária para a construção da ordem social (ESCORSIM NETTO, 2011). Sendo assim, xs conservadorxs consideram que xs professorxs têm um papel com um roteiro a seguir, já que elxs são xs 
instrutorxs que transmitirão os valores necessários para a reforma moral da sociedade. Todavia, segundo xs adeptxs do Escola sem Partido, como xs professorxs, no Brasil, não estariam atuando como instrutorxs da moralidade e sim como doutrinadorxs políticxs e ideológicxs, xs primeirxs passaram a perseguir xs segundxs, pois, para aquelxs, estxs não cumpririam o seu papel (SEPULVEDA; SEPULVEDA, 2018).

Apesar da resistência da direção escolar a que desenvolvêssemos atividades que combatessem a homofobia e a lesbofobia, conseguimos fazer uma atividade denominada caixa de dúvidas, na tentativa de que xs estudantes, professorxs e funcionárixs pudessem valorizar e aceitar as diferenças de gêneros e sexualidades.

Durante uma semana, deixamos no pátio da escola uma caixa, onde qualquer membro da comunidade escolar pôde depositar por escrito suas inquietações quanto às questões de gêneros e sexualidades no ambiente escolar e também em relação às práticas de discriminação contra alunxs LGBTIS+. Vale ressaltar que espalhamos diversos cartazes, pela escola, informando sobre a caixa e a atividade.

Ao pegarmos a caixa, após uma semana inteira na escola, percebemos que foi nela depositado um bom número de cartões, o que sinalizava, para nós, naquele momento, que uma boa parte da comunidade escolar estava interessada na atividade. Ao abrirmos a caixa de dúvidas, nos deparamos com comentários bem diversificados, desde perguntas extremamente relevantes, passando por piadas sem sentido, indo até insinuações LGBTIfóbicas.

Em seguida, fizemos uma roda de conversa com xs estudantes, professorxs e funcionárixs para trabalharmos as dúvidas que foram depositadas na caixa. Um número grande de interessadxs se fez presente, para que pudéssemos debater as questões da caixa de dúvidas.

O objetivo de se realizar uma roda de conversa é um aprendizado mútuo com a troca de experiências. É sempre compartilhar um fato, seja ele bom ou ruim, uma inquietude ou uma satisfação, uma dúvida ou afirmação, descoberta ou indignação, decisão ou uma solução, ou seja, independente de qual for o motivo, ela sempre levará à aprendizagem pela troca e reconstrução de conceitos dos participantes. (SILVA, 2012, p. 55).

O próximo passo da atividade seria levarmos um cartaz com todas as perguntas respondidas e deixá-lo em algum mural da escola; porém, quando fomos conversar com a diretora, esta nos disse que era melhor encerrar a pesquisa, pois algumas pessoas estavam insinuando que a própria direção estaria incentivando atividades sobre gêneros e sexualidades. Essa atitude para nós nos deu indícios de que o medo teria atingindo a gestora da instituição escolar.

\section{Considerações finais}


Vivemos tempos conservadores (CUEVA, 1989), em que se ataca a educação brasileira de forma extremamente eficiente. Este artigo se propôs a demonstrar esses ataques e como os grupos conservadores se articularam, com tal intuito.

Como demonstramos no texto, o conservadorismo, aqui entendido como uma narrativa que naturaliza a desigualdade social, se fortaleceu no campo educacional a partir de grupos religiosos, ou melhor, da ação de bancadas religiosas organizadas na política em todos os entes federados.

A força desses grupos foi tão grande que eles conseguiram, de forma inédita, aprovar a inserção da disciplina de Ensino Religioso na BNCC (BRASIL, 2017) com status de ciência humana. Ao mesmo tempo, obtiveram o êxito de retirar o termo gênero da maior parte da legislação educacional do Brasil, interferindo até nas práticas escolares. Tais grupos conservadores receberam, a partir de 2019, apoio do governo executivo central, o que nos aponta para um futuro muito difícil e de possível retrocesso das conquistas sociais alcançadas, principalmente na educação, nas últimas décadas.

Em suma, as propostas de educação originárias do atual governo sofrem forte ingerência de grupos religiosos. Tal ingerência fere o princípio da laicidade do Estado, comprometendo assim a própria democracia. Sem laicidade, não existe democracia e, sem democracia, não existe laicidade. Nós, educadorxs, precisamos nos manter atentos e na luta pela defesa da escola pública laica e democrática.

\section{Notas}

1 O uso do $x$ nas palavras, do ponto de vista linguístico e gramatical, é uma forma de estabelecer uma linguagem escrita que expresse maior igualdade entre homens e mulheres. Há dois gêneros na língua portuguesa: o feminino e o masculino, sendo o masculino o termo não marcado e o feminino o termo marcado pela terminação $a$ (embora haja casos de substantivos masculinos precedidos de artigo definido $o$, que possuem terminação em $a$, como em o artista, o colega, $o$ poeta). O masculino, além de determinar o sexo masculino, também tem uma função generalizante, como quando dizemos o homem no sentido de ser humano, por exemplo. Essa generalização pode ocorrer tanto no singular quanto no plural dos substantivos. No contexto de manifestações pela melhoria da educação pública e melhores condições de trabalho e salário, por exemplo, poderíamos encontrar ambas as manchetes de jornais: “O professor está em greve” e "Professores estão em greve"; nos dois casos, o masculino, seja singular ou plural, tem função generalizante. Essa generalização exercida pelo gênero masculino é considerada sexista e machista por certos grupos e indivíduos, resultando assim em propostas por um gênero não sexista a ser adotado em português. O uso do $x$ é uma tentativa de, no âmbito da escrita, tornar a língua mais democrática.

2 Campo é um conceito de Pierre Bourdieu (1989) e significa um espaço de luta de agentes e de instituições pelo monopólio da violência simbólica legítima, no seu interior, e pela posse do capital próprio desse campo.

3 A BNCC surgiu após a sanção presidencial do Plano Nacional de Educação pela lei n. 13.005, de 25 de junho de 2014, que deu a partida para a elaboração daquela base curricular (Brasil, 2014). A princípio, a construção da nova BNCC previa ampla participação da sociedade civil; todavia, ela acabou atendendo à corrente mais forte, a dos entusiastas da avaliação, em sua maioria ligados a interesses privatistas, para quem o currículo carece de objetivos específicos de aprendizagem, fixados para cada ano. O processo de produção da BNCC teve início em dezembro de 2012 na Secretaria da Educação Básica (SEB) do Ministério da Educação (MEC).

4 Os criadores do termo "ideologia de gênero" se baseiam em dois livros para compor essa narrativa: primeiramente, no livro da militante pró-vida Dale O’Leary (1997), denominado Agenda de gênero. O’Leary participou de conferências da Organização das Nações Unidas (ONU), em Cairo, em 1994, e em Pequim, em 1995, como delegada. Nas descrições dessas conferências, ela enfatiza, de acordo com sua interpretação, a ação das feministas de impor o conceito gênero e 
como, a partir dali, a ONU assumiu a chamada perspectiva de gênero nas políticas públicas em relação aos direitos das mulheres. O outro embasamento utilizado na construção da argumentação da tal "ideologia de gênero" é o livro do advogado argentino Jorge Scala (2011), intitulado Ideologia de gênero: neototalitarismo e a morte da família. O autor é um membro do movimento pró-vida, defensor das causas antiaborto e conhecido por ser contra os direitos das mulheres. Em suas argumentações, faz interpretações tendenciosas dos estudos de gêneros, que são convenientemente usados, distorcidos, desqualificados e acusados de prejudiciais a todas as sociedades.

5 É necessário enfatizar que acrescentamos a letra $s$ à referida sigla por considerarmos que xs simpatizantes e parceirxs dessas identidades também vivenciam, em seus cotidianos, procedimentos de discriminação, preconceitos e exclusão, os quais podem ser entendidos como procedimentos diferentes, pois nenhuma pessoa sente esses processos da mesma forma, conquanto sofram essas discriminações. De acordo com Goffman (1988), as pessoas que compartilham suas vidas com as de indivíduos estigmatizados, que sofrem processos de discriminação e preconceito, são definidxs como suxs iguais e denominadxs de informadxs. São pessoas cuja situação de vida ou militância as levou a serem simpatizantes da causa e que, por isso, possuem aceitação do grupo; por outro lado, também sofrem da maior parte das privações, preconceitos e discriminações típicas do grupo com o qual assumiram conviver e, juntamente, militar. Também adotamos a letra $s$ como expressão de solidariedade: solidárixs à causa.

O Movimento Escola sem Partido foi criado pelo advogado Miguel Nagib, em 2004, para combater o que ele chamou de doutrinação política, nas escolas. Tal doutrinação seria fruto de um nominado marxismo cultural, que teria se espalhado pela sociedade e pelas escolas do Brasil, sendo especialmente difundido pelos governos do Partido dos Trabalhadores (PT).

7 Desde a segunda metade dos anos de 1990, quando o neoliberalismo se tornou política de Estado, muitos empresários começaram a se interessar pelo problema educacional brasileiro e se organizaram com a intenção de ocupar o aparelho de Estado, com suas demandas. Entre os diferentes grupos de empresários que se formaram no período, nacionais e internacionais, o que mais se destacou, principalmente por ter apoio do principal grupo de comunicação do Brasil (Organizações Globo), foi o movimento Todos pela Educação (TPE). Tal organização concentra diferentes grupos econômicos: Grupo Gerdau, Grupo Suzano, Banco Itaú, Banco Bradesco e outras instituições.

8 Gayfobia é um termo usado para designar uma forma de preconceito e aversão aos gays em geral, apresentando-se como uma série de atitudes e sentimentos negativos (de aversão, desprezo, ódio ou medo) manifestados diante daquelas pessoas. Esses sentimentos têm gerado práticas de discriminação e perseguição, assim como crimes, entre eles homicídios.

9 A lesbofobia (ou lesbifobia) abarca múltiplas formas de reação conservadora em relação às mulheres lésbicas como pessoas, como um casal ou como um grupo social. Com apoio nas categorias de sexo ou gênero biológico, orientação sexual, identidade lésbica e expressão de gênero, a reação conservadora engloba manifestações de preconceito, discriminação e abuso. A lesbofobia é o sexismo contra as mulheres e está relacionado com a gayfobia e vice-versa. Cynthia Petersen, professora de Direito na Universidade de Ottawa, definiu lesbofobia como também incluindo “o medo que as mulheres têm de amar outras mulheres, assim como o medo que os homens (incluindo gays) têm das mulheres não amá-los”. Assim, a lesbofobia apresenta-se como uma série de atitudes conservadoras e sentimentos negativos (de aversão, desprezo, ódio ou medo) expressados diante das lésbicas, pois estas vivenciam suas sexualidades fora da norma heterossexual. Esses sentimentos, como a gayfobia, também têm gerado práticas de discriminação e perseguição e crimes como os homicídios. As lésbicas, assim como os gays, são vítimas de discriminação e muitas vezes tratadas por termos depreciativos. Uma das maiores discriminações de que são vítimas é a invisibilidade.

\section{Referências}

BLANCARTE, R. O porquê de um Estado laico. In: LOREA, R. A. Em defesa das liberdades laicas. Porto Alegre: Livraria do Advogado Editora, 2008.

BONALD, L. G.Ambroise de. Essai Analytique sur les Lois Naturelles de l'Ordre Social ou Du Pouvoir, du Ministre et du Sujet dans la Societé. Gallica, Bibliothéque Numérique de la Bibliothéque Nationale de France, 1802.

BONAZZI, T. Conservadorismo. In: BOBBIO, Norberto; MATTEUCCI, Nicola; PASQUINO, Gianfranco. Dicionário de política. Brasília: Editora UNB; São Paulo: Imprensa Oficial do Estado de São Paulo, 2000. 
BOURDIEU, P. O Poder Simbólico. Lisboa: DIFEL, 1989.

BRASIL. Lei n. 9.394, de 20 de dezembro de 1996. Estabelece as diretrizes e bases da educação nacional. Diário Oficial da União, Brasília, p. 27.833, 23 dez. 1996. Disponível em: <http://www. planalto.gov.br/ccivil_03/Leis/L9394.htm>. Acesso em: 10 ago. 2019.

. Lei n. 10.639, de 9 de janeiro de 2003. Altera a lei n. 9.394, de 20 de dezembro de 1996, que estabelece as diretrizes e bases da educação nacional, para incluir no currículo oficial da rede de ensino a obrigatoriedade da temática "História e Cultura Afro-Brasileira", e dá outras providências. Diário Oficial da União, Brasília, p. $1, \quad 10 \quad$ jan. 2003. Disponível em: <http://www.planalto.gov.br/ccivil_03/leis/2003/l10.639.htm>. Acesso em: 13 ago. 2019.

Lei n. 12.796, de 4 de abril de 2013. Altera a lei n. 9.394, de 20 de dezembro de 1996, que estabelece as diretrizes e bases da educação nacional, para dispor sobre a formação dos profissionais da educação e dar outras providências. Diário Oficial da União, Brasília, p. 1, 5 abr. 2013a. Disponível em: $<$ http://www.planalto.gov.br/ccivil_03/_ato2011-2014/2013/lei/L12796.htm>. Acesso em: 29 ago. 2019.

. Ministério da Educação. Secretaria de Educação Básica. Secretaria de Educação Continuada, Alfabetização, Diversidade e Inclusão. Conselho Nacional da Educação. Diretrizes Curriculares Nacionais Gerais da Educação Básica/ Ministério da Educação. Secretária de Educação Básica. Diretoria de Currículos e Educação Integral. - Brasília: MEC, SEB, DICEI, 2013.

Lei n. 13.005, de 25 de junho de 2014. Aprova o Plano Nacional de Educação - PNE e dá outras providências. Diário Oficial da União, p. 1, 26 jun. 2014. Disponível em: <http://www.planalto.gov.br/ccivil_03/_ato2011-2014/2014/lei/113005.htm>. Acesso em: 29 ago. 2019.

BRASIL. Ministério da Educação. Conselho Nacional de Educação. Câmara de Educação Básica. Resolução n. 4, de 13 de julho de 2010. Define Diretrizes Curriculares Nacionais para a Educação Básica. Diário Oficial da União, Brasília, p. 824, 14 jul. 2010. Disponível em: <http://www.prograd.ufu.br/sites/prograd.ufu.br/files/media/documento/resolucao_cneceb_no_4_de_13_d e_julho_de_2010.pdf > . Acesso em: 22 ago. 2019.

BRASIL. Ministério da Educação. Base Nacional Comum Curricular: educação é a base. Brasília, 6 abr. 2017. Disponível em: <www.observatoriodoensinomedio.ufpr.br/wp-content/uploads/2017/04/BNCCDocumento-Final.pdf > . Acesso em: 29 ago. 2019.

BURKE, Edmund. Einloft Neto, Herculano de Lima (tradução). Reflexões sobre a Revolução em França, v. 1, 2012.

BUTLER, J. Problemas de Gêneros: feminismo e subversão da identidade. Rio de Janeiro: Civilização Brasileira, 2017.

CANCIAN, N. Ministério tira 'identidade de gênero' e ‘orientação sexual' da base curricular. Folha de S.Paulo, São Paulo, 6 abr. 2017. Disponível em: <https://www1.folha.uol.com.br/educacao/2017/04/1873366ministerio-tira-identidade-de-genero-e-orientacao-sexual-da-base-curricular.shtml>. Acesso em: 29 ago. 2019.

CERTEAU, M. A invenção do cotidiano: artes de fazer. Petrópolis, RJ: Vozes, 2001.

CORRÊA, R. A LGBTIfobia influenciada pelo discurso judaico-cristão em uma unidade escolar pública no município de São Gonçalo - RJ. 2019. Monografia (Licenciatura em Geografia) - Faculdade de Formação de Professores, Universidade do Estado do Rio de Janeiro, São Gonçalo, 2019.

CUEVA, A. Tempos conservadores. São Paulo: Hucitec, 1989.

CUNHA, L. A. A entronização do Ensino Religioso na Base Nacional Curricular Comum. Educação \& Sociedade, v. 37, n. 134, p. 266-284, jan./mar. 2016. Disponível em: <http://www.scielo.br/pdf/es/v37n134/1678-4626-es-37-134-00266.pdf>. Acesso em: 25 ago. 2019.

CUNHA, L. A. Três décadas de conflito em torno do ensino público: laico ou religioso?. Educação \& Sociedade, v. 39, n. 145, out./dez. 2018. 
DORVILLÉ, L. F. M.; SELLES, S. L. E. Criacionismo: transformações históricas e implicações para o ensino de ciências e biologia. Cadernos de Pesquisa, v. 46, n. 160, abr.jun. 2016.

ESCORSIM NETTO, L. O conservadorismo clássico: elementos de caracterização e crítica. São Paulo: Cortez, 2011.

FERNANDES, V. C. (As)Simetria nos sistemas públicos de ensino fundamental em Duque de Caxias (RJ): a religião no currículo. 2014. 238 f. Tese (Doutorado em Educação) - Faculdade de Educação, Universidade Federal do Rio de Janeiro, Rio de Janeiro, 2014.

FRIGOTTO, G. A gênese das teses do Escola sem Partido: esfinge e ovo da serpente que ameaçam a sociedade e a educação. In: FRIGOTTO, Gaudêncio (Org.). Escola "sem" partido: esfinge que ameaça a educação e a sociedade brasileira. Rio de Janeiro: Uerj; LPP, 2017.

GINZBURG, Carlo. Mitos, emblemas e sinais. São Paulo: Companhia das Letras, 1989.

GOFFMAN, E. Estigma: notas sobre a manipulação da identidade deteriorada. Rio de Janeiro: LTC, 1988.

HIRSCHMAN, A. A retórica da intransigência: perversidade, futilidade, ameaça. São Paulo: Companhia das Letras, 1992.

LOPES, A. C. Por um currículo sem fundamentos. Linhas Críticas, Brasília, v. 21, n. 45, p. 445-466, 2015. Disponível em: <http://periodicos.unb.br/index.php/linhascriticas/article/view/4581/4179>. Acesso em: 20 ago. 2019.

LOSCHI, M. Desemprego recua para 12\%, mas população subocupada é a maior desde 2012. Agência IBGE Notícias, Rio de Janeiro, 31 jul. 2019. Disponível em: <https://agenciadenoticias.ibge.gov.br/agencianoticias/2012-agencia-de-noticias/noticias/25093-desemprego-recua-para-12-mas-populacao-subocupadae-a-maior-desde-2012>. Acesso em: 28 ago. 2019.

LÖWY, M. Ideologias e ciências sociais: elementos para uma análise marxista. São Paulo: Cortez, 1991.

LÖWY, M; SAYRE, R. Revolta e melancolia. São Paulo: Boitempo, 2015.

MACEDO, E. As demandas conservadoras do movimento Escola sem Partido e a Base Nacional Curricular Comum. Educação \& Sociedade, v. 38, n. 139, abr.-jun. 2017.

MANNHEIM, K. Ideologia e utopia. Rio de Janeiro: Zahar Editores, 1972.

MANNHEIM, K. O pensamento conservador. In: MANNHEIM, Karl. Essays on sociology and social psychology. Londres: Routledge and Kegan Paul, 1959. p. 74-119.

MAISTRE, J. Lettre A M.. In: le Marquis D’Azeglio, 21/02/1821. Oeuvres complètes de Joseph de Maistre. Lyon: Vitte et Perussel, vol.XIV, 1886. p.258- 259.

MOORE JUNIOR, B. As origens sociais da ditadura e da democracia: senhores e camponeses na construção do mundo moderno. São Paulo: Martins Fontes, 1975.

MOURA, F. P. Conservadorismo cristão e perseguição aos estudos de gênero: a quarta versão da BNCC. Communitas, v. 2, 2018.

O’LEARY, D. The gender agenda. Lafayette: Vital Issues Press, 1997.

OLIVEIRA, I. B. Certeau e as artes de fazer: as noções de uso, tática e trajetória na pesquisa em Educação. In: OLIVEIRA, Inês Barbosa; ALVES, Nilda. Pesquisa nos/dos/com os cotidianos das escolas: sobre rede de saberes. Petrópolis: DP\&A, 2008.

PENNA, F. A. O Escola sem Partido como chave de leitura do fenômeno educacional. In: FRIGOTTO, Gaudêncio (Org.). Escola "sem" partido: esfinge que ameaça a educação e a sociedade brasileira. Rio de Janeiro: Uerj; LPP, 2017.

PEREIRA, T. V.; COSTA, H. H. C.; CUNHA, E. V. R. Uma base à Base: quando o currículo precisa ser tudo. Revista de Educação Pública, v. 24, n. 56, 2015. Disponível em: $<$ http://periodicoscientificos.ufmt.br/ojs/index.php/educacaopublica/article/view/2377/pdf >. Acesso em: 19 ago. 2019. 
SCALA, J. Ideologia de gênero: neototalitarismo e a morte da família. São José dos Campos: Katechesis, 2011.

SILVA, A. A roda de conversa e sua importância na sala de aula. 2012. 75 f. Monografia (Licenciatura Plena em Pedagogia) - Instituto de Biociências, Universidade Estadual Paulista, Rio Claro, 2012.

SILVA, O. J. da. Livros didáticos para a revolução socialista bolivariana. [S.1.]: Escola sem Partido, [201-]. Disponível em: <http://www.escolasempartido.org/livros-didaticos-categoria/459-livros-didaticos-para-arevolucao-socialista-bolivariana>. Acesso em: 29 ago. 2019.

SEPULVEDA, D.; SEPULVEDA, J. A. Conservadorismo, gêneros e sexualidades: temáticas que se entrelaçam nas pesquisas do GESDI e do GEPCB. In: SEPULVEDA, D.; AMARO, Ivan, Gêneros, sexualidades e educação na ordem do dia. Curitiba: CRV, 2018.

SEPULVEDA, D.; SEPULVEDA, J. A. A disciplina Ensino Religioso: história, legislação e práticas. Educação, v. 42, n. 1, jan./abr. 2017.

SEPULVEDA, J. A.; SEPULVEDA, D.; FERNANDES, V. C. Ensino Religioso e laicidade: suas implicações para a implementação da democracia nas escolas. Revista Contemporânea de Educação, v. 10, n. 19, 2015.

SILVA, M. V.; SANTOS, J. M. C.T. A BNCC e as implicações para o currículo da educação básica. In: Congresso Nacional da Diversidade, 1., 2018, Natal. Anais... Natal: Conadis, 2018. Disponível em <https://editorarealize.com.br/revistas/conadis/trabalhos/TRABALHO_EV116_MD1_SA13_ID786_0810 2018110158.pdf>. Acesso em: 27 ago. 2019.

THOMPSON, E. P. Miséria da teoria ou um planetário de erros: uma crítica ao pensamento de Althusser. Rio de Janeiro: Jorge Zahar, 1981.

THOMPSON, E. P. As peculiaridades dos ingleses e outros ensaios. Campinas: Editora da Unicamp, 2012. WILLIAMS, R. Cultura e sociedade: de Coleridge a Orwell. Petrópolis: Vozes, 2011.

\section{Correspondência}

José Antonio Sepulveda: Professor do Programa de Pós-Graduação em Educação da Universidade Federal Fluminense. Professor Adjunto III da Faculdade de Educação da Universidade Federal Fluminense. Doutor em Educação pela Universidade Federal do Rio de Janeiro (2010). Mestre em Educação pela Universidade Federal do Rio de Janeiro (1999). Especialista em História das Relações Internacionais pela Universidade do Estado do Rio de Janeiro (1995). Possui Licenciatura e Bacharelado em História (1991). Líder do Grupo de Estudos e Pesquisa: Os Impactos do Conservadorismo na Educação Brasileira da UFF. Sub-líder do Grupo de Pesquisa Gêneros, Sexualidaes e Diferenças nos Vários EspaçosTempos Cotidianos da UERJ/FFP

E-mail: jamsepulveda3@hotmail.com

Denize Sepulveda: Professora do Programa de Pós-Graduação em Educação Processos Formativos e Desigualdades Sociais (PPGedu) da UERJ/FFP. Professora Adjunta da Universidade do Rio de Janeiro no Departamento de Educação - FFP. Pós-doutora pelo Programa de Pós-Graduação em Educação da UERJ /PROPED (2014 - 2016). Doutora pelo Programa de Pós-Graduação em Educação da UERJ (2012). Mestre em Educação pela Universidade Federal Fluminense (2003). É bacharel e licenciada em História (1993). Coordenadora do Grupo de Pesquisa Gêneros, Sexualidades e Diferenças nos Vários EspaçosTempos Cotidianos da UERJ/FFP. Sub-líder do Grupo de Estudos e Pesquisa e do Diretório Os Impactos do Conservadorismo na Educação Brasileira da UFF. Sub-líder do Diretório "Diálogos Escolas-Universidade: Processos Formativos, Currículos e Cotidiano” da UERJ/FFP.

E-mail: denizesepulveda@hotmail.com 
Texto publicado em Currículo sem Fronteiras com autorização dos autores 